\title{
Preventable complications of pterygium excision with beta-irradiation
}

\author{
MALGOLM E. GAMERON \\ Brisbane, Australia
}

During an extensive experience of 15 years, with many thousands of cases of pterygium excision with beta-irradiation, I have seen no serious complications until recently. An occasional irritable eye has persisted for several months but there have been no indolent ulcers or lost eyes, until the last year, when there have been two very irritable eyes, two extremely indolent scleral ulcers, and a fifth case in which the ulcer perforated and the eye was lost.

I have investigated these five cases and have come to the conclusion that the grim results in three were due to faulty surgical technique (mainly too many applications by a largetipped cautery), in another to impaired blood supply to the anterior segment, and in the last too much beta-irradiation.

\section{Case reports}

CASE I. AN IRRITABLE EYE

A man aged 76 yrs had a pterygium excised from the left eye with beta-irradiation $(2,200$ rads with a $16-\mathrm{mm}$. circular applicator) on August 10 , I970. The eye was irritable for 4 months afterwards, but when he was last seen on January 28, 197 I, the eye was quiet and there was no irritation. Photography on February 2 revealed about nine large holes in the sclera about $1 \mathrm{~mm}$. in width (Fig. I). Investigation showed that the surgeon had used the large-diameter probe (on the left in Fig. 2). The probe used by the author and recommended for coagulation of bloodvessels in the bare area is shown on the right in Fig. 2.

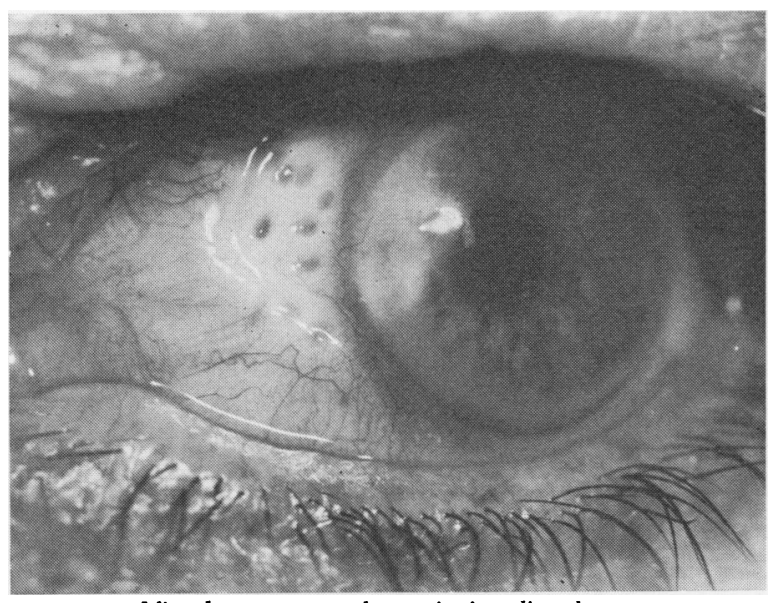

F I G. I Nine large cautery burns in irradiated area.

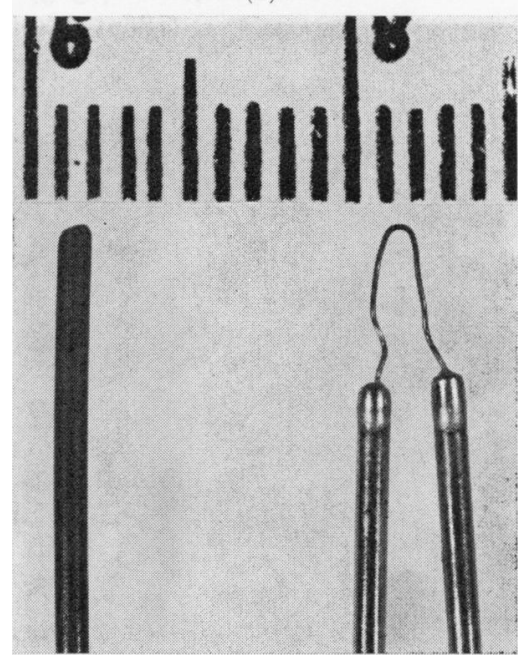

FIG. 2 Large-diameter probe, heated by a methylated spirit flame, is shown on the left. The smaller one on the right (which is recommended) is activated by a pencil battery. (Scale in $\mathrm{mm}$.) 
CASE 2. AN IRRITABLE EYE

A woman aged 46 yrs had bilateral nasal pterygia excised on January 29, 1964, with accompanying beta-irradiation (2,200 rads with a $16-\mathrm{mm}$. circular applicator). In August, 1964, both the operated areas appeared to be satisfactory. She next reported in February, 1969, complaining of an irritable left eye. The irradiated area was avascular and contained two staining plaques and some telangiectatic vessels (Fig. 3). The eye was more comfortable with no staining in December, 1969, but intraocular examination showed severe attenuation of the retinal arterioles with swollen venules and exudates at the maculae. The left vitreous was full of opacities but the right was found to be clear. It was then learned that she had been severely hypertensive for some years and was receiving Ismelin $40 \mathrm{mg}$./day and a diuretic. When she was last seen on March 12, 197 I, the fundi appeared much healthier. There were no exudates or haemorrhages and the arterioles were less attenuated. The excision sites attracted no undue attention and the patient said that the eyes felt normal.

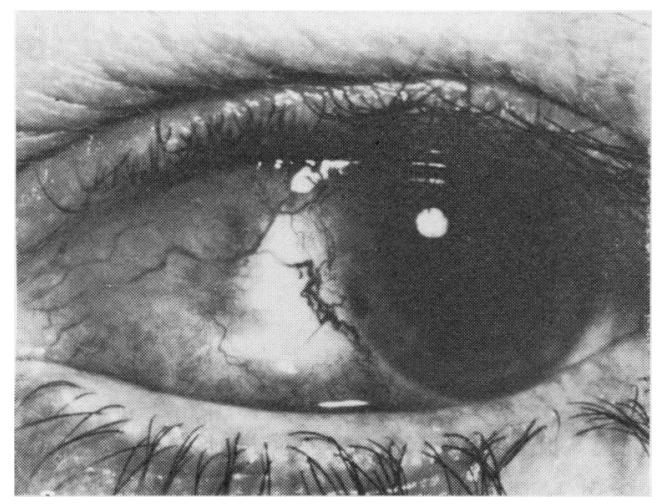

FIG. 3 The irradiated area is a dense white colour. It contains two staining plaques (not visible in the photograph) and several telangiectatic vessels

\section{CASE 3. AN INDOLENT ULGER}

A woman aged 52 yrs had a left nasal pterygium excised with beta-irradiation $(2,200$ rads with a I6-mm. circular applicator) on July 26,1968 . The eye was irritable afterwards and 2 years later she reported with pain in and behind the affected eye, which was then red. On October 6, 1970, an indolent brown ulcer several millimetres in diameter was seen in the middle of the bare sclera left after excision (Fig. 4). This ulcer has an irregular edge and does not now resemble that due to the rounded cautery point illustrated in Fig. 2. It is thus impossible to say categorically whether cauterization was a factor or not, but subsequent experience with the next case makes it not improbable. At the last examination on March 12, 1971, the patient said that the eye was always slightly irritable. There was mild injection and the ulcer was paler.

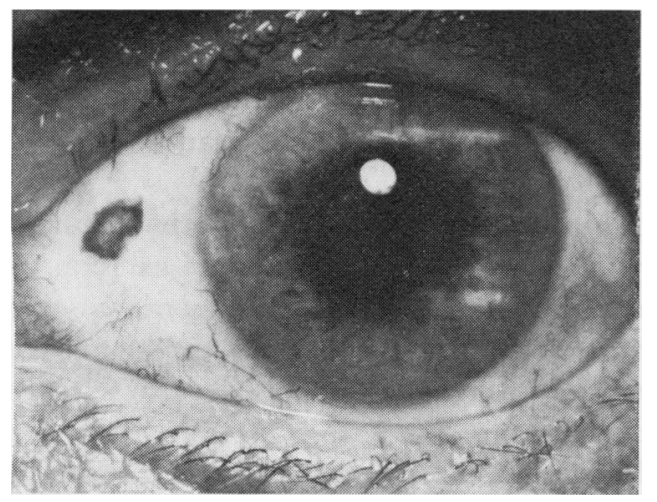

FIG. 4 Indolent brown ulcer with irregular black edge in centre of irradiated area 
CASE 4. SCLERAL ULGER

A man aged 66 years had a pterygium excised from the left eye with beta-irradiation $(2,200$ rads with a $16-\mathrm{mm}$. circular applicator) on August 22, 1969. The surgeon recorded in the operation notes that extensive cautery was necessary. On November 28 , 1969, the patient reported with periodic pain in the left eye and in May, 1970, there was an obvious deep scleral ulcer $3 \mathrm{~mm}$. from the limbus at 8 o'clock (Fig. 5). The ulcer has gradually filled in and, when he was last seen on March I2, 197 I, the patient said that there was no discomfort.

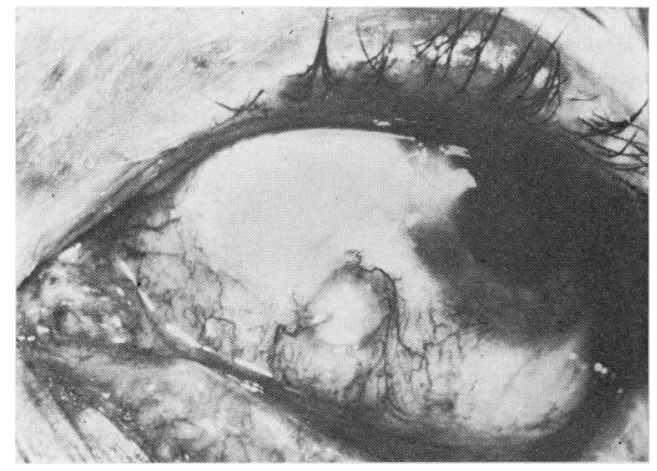

FIG. 5 Hemispherical ulcer $2 \mathrm{~mm}$. in diameter in lower part of irradiated area

CASE 5. LOSS OF EYE

A woman aged 58 yrs had a recurrent nasal pterygium excised from the right eye with beta-irradiation in another state in November, 1965. No notes of the operation are available, but the radiotherapy details are as follows: three doses of 1,200 rads given at weekly intervals to the excision site, the beginning on the 12 th postoperative day. The strontium 90 plate was $10 \mathrm{~mm}$. in diameter and applied directly to the eye. To cover the excised area two fields were chosen and these overlapped each other in the centre of the irrradiated area. Thus, while most of the area received 3,6oo rads, the overlapping central portion received 7,200 rads.

The patient came under my observation in January, 1970, with a thinned area of the sclera corresponding to the overlapping area of irradiation. The cornea was cloudy and there was chemosis, hypopyon, and an opaque vitreous. Pseudomonas was cultured and, although there was temporary response to parenteral and subconjunctival antibiotics, the eye was later eviscerated.

\section{Discussion}

These results are, of course, unacceptable, and I have not previously seen such results in a large series of cases. Careful investigation shows that in Cases I, 3, and 4 the complications are probably due to a combination of poor surgical technique with beta-irradiation of the excised area. In Case 2, the irradiation, together with an impaired blood supply to the anterior segment, was probably responsible for the irritable eye. In Case 5, in which the eye had to be eviscerated, overdosage with beta-irradiation was the probable cause.

Many surgeons consider the humble pterygium to be unworthy of their talents and sometimes for this reason, or under pressure of work, delegate the excision to junior staff, who in turn treat the condition in cavalier fashion, with, in some cases, poor results. The Latin adage non vi, sed arte (not with strength, but with skill) applies to the pterygium as well as to the cataract, especially where beta-irradiation is used. No scleral tissue should ever be destroyed in a pterygium operation, but it may be damaged-by the scalpel blade or by the cautery point. The cornea fits into the scleral rim much as a glass face 
fits into a watch. In the conventional method of excision therefore, beginning at the apex, it is very easy when the blade reaches the limbus to cut into or excise a piece of sclera. Beta-irradiation of this injured sclera may then produce an irritable eye. To avoid cutting the sclera when the limbus is reached, the blade must be angled anteriorly. In primary pterygia there is only very loose connective tissue between the base of the pterygium and the sclera and this is very easily divided. In recurrent pterygia the union may be dense, and more care must be taken to separate the pterygium from the sclera without incising the latter. It is scleral incision or excision which produces the bleeding necessitating cauterization. The vessels of the connective tissue soon stop bleeding spontaneously, but the scleral vessels are more persistent and their cauterization with the mediaeval instrument shown in Fig. 2 (left), together with beta-irradiation, sets the stage for later complications. There is no real necessity for cauterization in any case of primary pterygium, and cauterization can be avoided in the great proportion of recurrent pterygia if a careful surgical technique is followed. The bleeding soon stops if the bloodvessels are ignored. In the very few cases of persistent bleeding, careful touching of the bleeding point by the fine cautery shown in Fig. 2 (right) is all that is necessary.

In Case 2, the irritable eye was no doubt due to the combination of surgery and betairradiation, but the fellow eye which underwent the same treatment showed no complications. Does the cause therefore lie in an increased radiosensitivity of the left as compared with the right eye, or elsewhere? I think the latter. In both the eyes of this patient there was a marked reduction in blood supply to the retina, and presumably to other parts of the eye, which was produced by a severe hypertension. This was manifested by gross narrowing of the retinal vessels, together with what was probably an intravitreal haemorrhage in the left eye. Again, the combination of impaired blood supply and beta-irradiation produced an irritable eye. This case shows that irradiation should not be carried out in eyes suffering from malignant hypertension or presumably after central venous thrombosis or after any scleral buckling technique that may impair the nutrition of the anterior segment.

Much thought has also been given to reducing the area of irradiation, and I have shown elsewhere (Cameron, I965, I968) that the irradiated area can be reduced without affecting the result. With this in mind, the Queensland Radium Institute has evolved a new strontium 90 applicator with an aperture $12 \mathrm{~mm}$. $\times 6 \mathrm{~mm}$. in the base, which is curved to fit the sclera (Figs $6 a, b$, overleaf). As in the previous model, the applicator can be swivelled in any direction and contains a shelf $\mathrm{I} \mathrm{cm}$. from the aperture on which the strontium 90 plate rests. One application of 2,200 rads is given immediately after surgery. In the occasional cosmetically unsatisfactory recurrence, re-excision and a further dose of 2,200 rads is advocated. There would seem little doubt in Case 5, in which the eye had to be eviscerated, that the 7,200 rads received by the sclera where the radiation fields overlapped produced scleral thinning and ulceration. It is noteworthy that in Cases 2 and 5 there was a quiescent period of 5 years after irradiation before complications ensued.

\section{Summary}

Serious complications in five cases of pterygium excision with beta-irradiation have been investigated. In three cases, the complications were probably due to the unnecessary destruction of scleral tissue during the operation. In another case, overdosage with betairradiation was probably the cause, and in yet another impaired blood supply to the anterior segment. Common errors in surgical technique are pointed out and a new strontium 90 applicator with a reduced aperture is illustrated. 


\section{References}

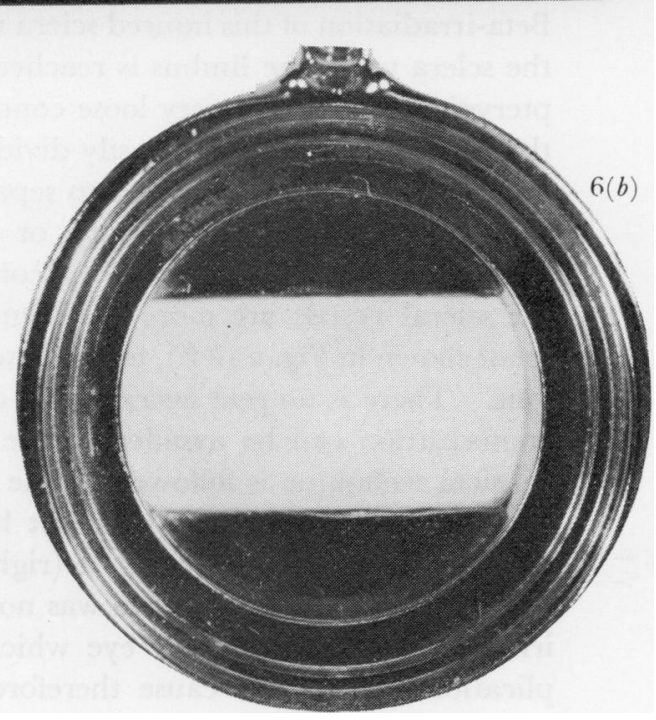

CAMERon, M. E. (1965) "Pterygium throughout the World". Thomas, Springfield, Ill. (1968) Brit. 7. Ophthal., 52, 562

FI G. 6(a) New strontium 90 applicator

(b) View from above showing I $2 \times 6 \mathrm{~mm}$. aperture and shelf on which the strontium 90 plate rests

\section{Q.R.I. No6}

